\title{
Expansão agrícola: elaboração de indicadores de sustentabilidade nas cadeias produtivas de Mato Grosso do Sul
}

\author{
Agricultural expansion: elaboration of sustainability indicators in the \\ production chains of Mato Grosso do Sul
}

\section{L'expansion agricole: le développement d'indicateurs de durabilité dans les chaînes de Mato Grosso do Sul de production}

La expansión agrícola: el desarrollo de indicadores de sostenibilidad em las cadenas de producción de Mato Grosso do Sul

\author{
Natascha Góes Cintra Borlachenco* \\ Ariadne Barbosa Gonçalves**
}

Recebido em 02/05/2016; revisado e aprovado em 03/08/2016; aceito em 08/09/2016

DOI: http:/ / dx.doi.org/10.20435/1984-042X-2017-v.18-n.1(09)

\begin{abstract}
Resumo: A Lei 12.651 surgiu da necessidade dos agropecuaristas em aumentar a sua produção versus a conservação da vegetação nativa. Assim, é possível aumentar a produção agropecuária consonante a Lei vigente, podendo citar o decreto que trata do Programa Mato Grosso do Sul Mais Sustentável. É importante que todos os proprietários de terra venham seguir as recomendações que estão previstas na lei para que o Estado não venha enfrentar a escassez de água que ocorreu em São Paulo em 2014.
\end{abstract}

Palavras-chave: Lei 12.651; agropecuária; agronegócio.

Abstract: Law 12,651 came from the need of ranchers to increase their production versus conservation of native vegetation. Thus, it is possible to increase the agricultural production in line with current law, can cite the decree deals with the Mato Grosso do Sul More Sustainable Program. It is important that all landowners will follow the recommendations that are provided by law so that the state will not face water shortages that occurred in São Paulo in 2014.

Key words: Law 12.651/12; agriculture; agribusiness.

Résumé: Loi 12651 est venue de la nécessité d'éleveurs à augmenter leur production par rapport à la conservation de la végétation indigène. Ainsi, il est possible d'augmenter la production agricole en conformité avec la loi actuelle, peut citer les décrets traite du Mato Grosso do Sul programme plus durable. Il est important que tous les propriétaires fonciers vont suivre les recommandations qui sont prévues par la loi pour que l'Etat ne sera pas face à des pénuries d'eau qui ont eu lieu à São Paulo en 2014.

Mots-clés: Loi 12.651; agriculture; agribusiness.

Resúmen: Ley 12.651 surgió de la necesidad de ganaderos para aumentar su producción en comparación con la conservación de la vegetación nativa. Por lo tanto, es posible aumentar la producción agrícola de acuerdo con la ley actual, se puede citar el Programa Mato Grosso Sul Más Sostenible. Es importante que todos los propietarios seguirán las recomendaciones que están previstas en la ley para que el Estado no se enfrentan a la escasez de agua que se produjeron en Sao Paulo en 2014. Palabras clave: Ley 12.651; la agricultura; la agroindustria.

\section{INTRODUÇÃO}

Desde 25 de maio de 2012, vigora a nova norma de proteção de vegetação no Brasil, a Lei n. 12.651 (BRASIL, 2012), denominada de Novo Código Florestal.
A nova lei dispõe sobre a proteção da vegetação nativa e tem como um dos objetivos estabelecer normas gerais sobre a proteção da vegetação das áreas de Preservação Permanente (APP) e Reserva Legal (RL) visando ao desenvolvimento

\footnotetext{
* Universidade Estadual de Mato Grosso do Sul, Campo Grande, Mato Grosso do Sul, Brasil.

** Universidade Católica Dom Bosco, Campo Grande, Mato Grosso do Sul, Brasil.
} 
sustentável (ZAKLA, 2013). Assim, essa lei surgiu do conflito entre a necessidade de aumento da produção agropecuária e a conservação da vegetação nativa. A proposta do novo código é mais flexível ou menos exigente em termos de áreas para conservação.

A vegetação nativa do território nacional corresponde a sessenta e dois por cento, sendo equivalente a 530 milhões de hectares. A maior parte dessas áreas encontra-se fragmentada em poder da propriedade privada (NOLTE et al., 2013). Assim, cabe ao legislador criar leis que protejam no mínimo as APPs para que a escassez hídrica não aconteça por falta de mata ciliar, pois ela é responsável pela manutenção dos ecossistemas aquáticos além de primordial importância para manutenção da qualidade da água (LIMA; ZAKIA, 2004 ) e evitar o assoreamento dos canais hídricos. Essa importância pode ser comprovada no Estado de São Paulo, que por supressão da mata ciliar em conjunto com a superpopulação, desperdício d'água, falta de chuvas, assoreamentos dos reservatórios de água, dentre outros, passou em 2014 pela maior seca das últimas décadas.

No entanto não foi o que aconteceu com a aprovação do Novo Código Florestal, que permitiu aos proprietários uma diminuição da vegetação das áreas de preservação, reduzindo os ambientes que deveriam ser reflorestados em aproximadamente 58\% (NOLTE et al., 2013). Sendo assim, o artigo n. 67 foi o que mais contribuiu para a redução do passivo ambiental, no qual se estabelece que, para propriedades de até quatro módulos fiscais, a RL será constituída com a área ocupada com a vegetação nativa existente em 22 de julho de 2008 (BRASIL, 2012).

Outro ponto também polêmico da Lei 12.651 é a que fala das anistias sobre pagamento de multas ou a desobrigação da recuperação da vegetação e incidem também sobre as propriedades com até quatro módulos fiscais, em áreas sensí- veis e de grande valor ecológico e social. Foram perdoados desmatamentos ilegais em várias APPs e autorizada a recomposição dessas áreas com eucalipto, soja ou qualquer espécie exótica. Essa lei também reduz a APP nas margens dos cursos d'água, o que antes previa uma faixa de 30 a 500 metros e agora prevê faixas menores de vegetação, entre 5 e 100 metros, uma redução considerável quando se trata em conservação da mata ciliar.

A falta de planejamento no uso e ocupação das terras em Mato Grosso do Sul (MS) tem acarretado graves prejuízos devidos à intensificação dos processos de degradação, sendo que a ocupação dessas terras é de grande vulnerabilidade ambiental. Assim, as APPs bem como a locação imprópria das estradas, em sua maioria sem dispositivos de drenagem, e também a adoção de práticas agropecuárias inadequadas, têm sido indicadas como os principais agentes da degradação no meio rural (CHAVES et al., 2012). Uma das principais causas da degradação do solo do MS é o superpastejo onde há excesso de animais na pastagem, sendo a produção irregular, comprometendo, todavia, a produtividade animal e o desgaste da pastagem, como exposto nos trabalhos de Souza (2010) e Santos e Comastri-Filho (2012).

A partir de meados do século XX, entrou em decadência o modelo de desenvolvimento em curso, o que oportunizou que outras atividades produtivas passassem a ser praticadas no MS. A economia que atualmente predomina no estado é o agronegócio da soja, eucalipto, cana-de-açúcar, pecuária extensiva, entre outros (DOMINGUES, 2011). As monoculturas de soja, cana, eucalipto e a pecuária, quando manejadas inadequadamente, trazem prejuízos ambientais, e isso comumente tem ocorrido nas áreas produtivas do estado. Assim, é importante para o produtor rural aplicar os indicadores de Desenvolvimento Sustentável, instrumentos essenciais para guiar a ação 
e subsidiar o acompanhamento e a avaliação do progresso alcançado rumo ao desenvolvimento sustentável, dentro da propriedade. Ressalta-se que este trabalho não tem como objetivo avaliar as áreas compreendidas pelo Pantanal sul-mato-grossense.

O Decreto n. 13.977, de 5 de junho de 2014, no seu art. 53, institui, no âmbito de Mato Grosso do Sul, o Programa de Regularização Ambiental denominado Programa MS Mais Sustentável, em atendimento ao estabelecido no Capítulo XIII da Lei Federal n. 12.651, de 2012, e no Capítulo III do Decreto Federal n. 7.830, de 2012. O Programa MS mais sustentável tem como principal objetivo proporcionar apoio à regularização ambiental de imóveis rurais com passivos ambientais em APP, RL ou de Áreas de Uso Restrito, com vistas a uma maior sustentabilidade socioeconômica e ambiental de MS (MATO GROSSO DO SUL, 2014).

A intensificação da produção sustentável de culturas busca aumentar a produção por unidade de área através do melhoramento de semente, inserção de polinizadores nas culturas, recomposição dos nutrientes no solo, dentre outros (FOOD AND AGRICULTURE ORGANIZATION OF THE UNITED NATIONS [FAO], 2010). Assim, com a regulamentação ambiental das propriedades rurais, os produtores não terão diminuição de produção se deixarem as técnicas rústicas e atrasadas de produção e se atualizarem com as novas tecnologia e maneiras de se produzir mais com menos área disponível. Para tanto, é necessário que os agropecuaristas estejam abertos às inovações e conhecimentos técnicos para melhor utilização da terra e água.

Existem diferentes métodos e interpretações para o desenvolvimento e uso de indicadores de sustentabilidade, que são metas e objetivos que visam ao bem-estar econômico e sustentável da propriedade. Os indicadores refletem os interesses de quantificar e avaliar a sus- tentabilidade da produção agropecuária, e têm crescido nos últimos anos devido à preocupação com a finitude dos recursos ambientais. Os indicadores podem ser separados em três modalidades, são eles: ambiental, econômico e social.

$\mathrm{O}$ uso de indicadores para avaliar o desenvolvimento sustentável de um grande número de processos e sistemas produtivos tem se multiplicado de tal forma, que eles têm sido elaborados tanto por instituições públicas quanto privadas e já incorporam os mais variados tipos de dimensões: aspectos econômicos, fatores sociais, desenvolvimento ambiental, evolução do conhecimento, diversidade cultural, influência política e outros. Salientase a necessidade de geração e delimitação de indicadores objetivos e mensuráveis na prática dentro das cadeias produtivas sempre respeitando a legislação vigente (HIRAKURI et al., 2014). Destarte, nas seções seguintes, são apresentados os indicadores de sustentabilidade das cinco grandes cadeias produtivas do Estado de Mato Grosso do Sul.

\section{2 ÁREA DE ESTUDO}

O Estado do Mato Grosso do Sul está localizado no planalto central brasileiro (Figura 1), possui aproximadamente 2,3 milhões de habitantes e faz fronteira com Bolívia, Paraguai e mais cinco estados brasileiros. Na maior parte do território do Estado, predomina o clima do tipo tropical, com chuvas de verão e inverno seco, caracterizado por médias termométricas que variam entre $26^{\circ} \mathrm{C}$ na baixada do Paraguai e $23^{\circ} \mathrm{C}$ no planalto. A pluviosidade é de aproximadamente $1.500 \mathrm{~mm}$ anuais. No extremo meridional, ocorre o clima tropical de altitude, em virtude de uma latitude um pouco mais elevada e do relevo de planalto. A média térmica é pouco superior a $20^{\circ} \mathrm{C}$, com queda abaixo de $18^{\circ} \mathrm{C}$ no mês mais frio do ano. Os cerrados recobrem a maior parte do Estado. Na planície aluvial do Pantanal, surge o 
chamado complexo do Pantanal, revestimento vegetal em que se combinam cerrados e campos, com predominância da vegetação de campos. As principais fontes econômicas do Estado são agricultura e pecuária (GUIMARÃES, 1999).

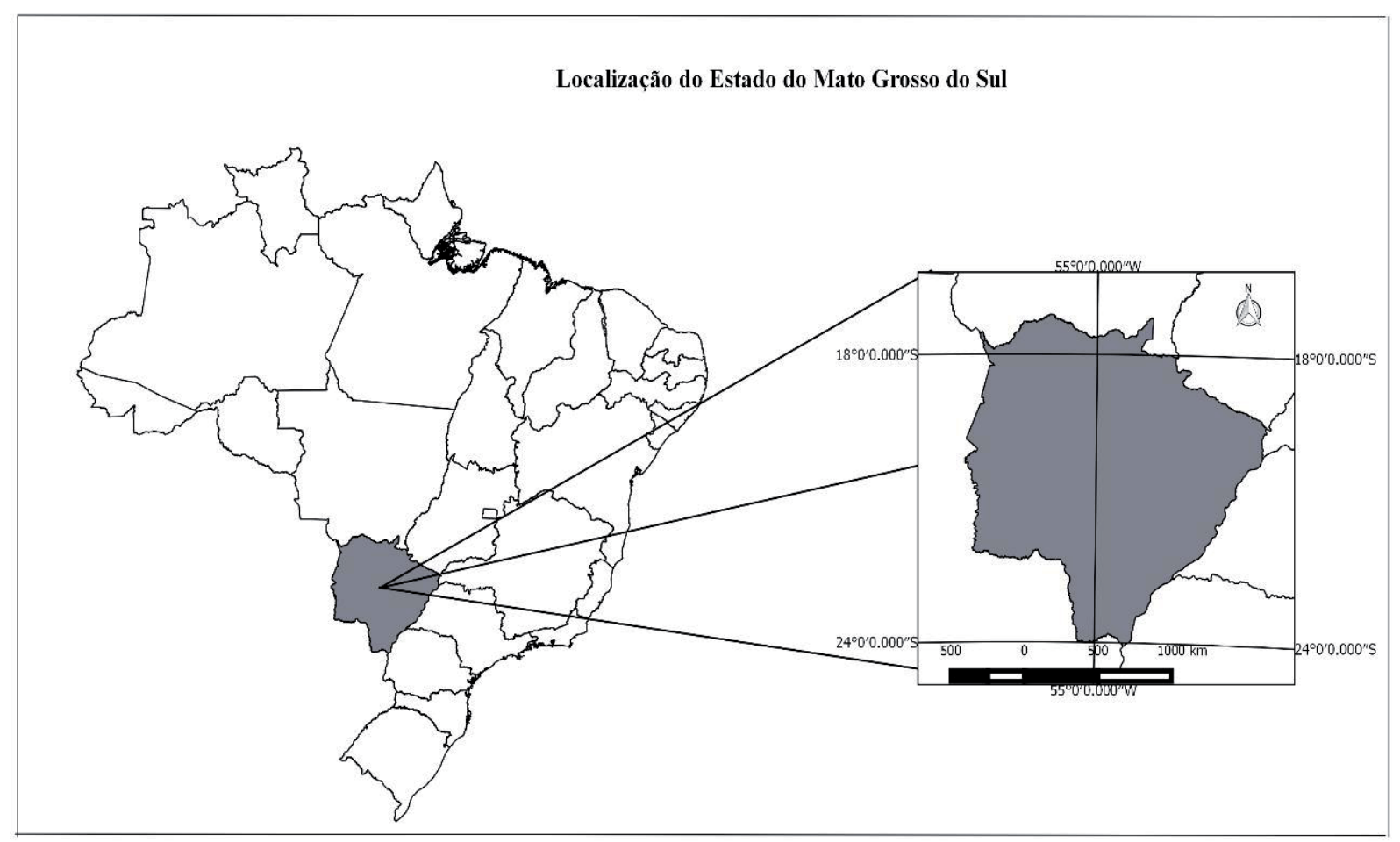

Figura 1 - Mapa de localização do Brasil, com destaque para o Estado de Mato Grosso do Sul

\section{DESENVOLVIMENTO}

\subsection{Soja}

Principal commodity do agronegócio brasileiro, que vem batendo recordes de safras ano após ano. No Centro-Oeste, ela se tornou a principal cultura produzida, uma vez que o cerrado possibilitou adaptação sem igual para sua consolidação. A região Centro-Oeste possui a maior área plantada com soja, e o MS ocupa uma importante posição nacional dentre os estados produtores de soja; na safra 2013/2014, foi responsável por uma produção de 6.148t de grãos, ficando em $5^{\circ}$ lugar entre os estados produtores de soja (COMPANHIA NACIONAL DE ABASTECIMENTO [CONAB], 2014a). A sojicultura é uma importante atividade agrícola geradora de renda e emprego, pois movimenta uma série de agentes eco- nômicos e institucionais, além disso, é um setor dinâmico e demandante de inovações e investimentos constantes em virtude do alto grau de competitividade a que está exposta (FAGUNDES; SIQUEIRA, 2013).

Segundo Lima-Filho et al. (2008), a cadeia produtiva da soja do MS apresenta os seguintes elos: Insumos, produção, transformação e distribuição. Quanto aos insumos, o Brasil possui 22 empresas para melhoramento genético, sendo que no estado está instalada a Empresa Brasileira de Pesquisa Agropecuária (EMBRAPA), que realiza pesquisas para diversos setores no agronegócio, desde melhoramento genético a ganhos e rendimentos produtivos. Na sua produção, as sobras da planta são utilizadas para fazer adubo, forragem e pastagem; o seu transporte é terceirizado, as empresas pagam royalties pelo uso de sementes, e quem regula o mercado são as empresas estatais. 
A transformação é feita em sua maioria por empresas multinacionais, e poucas nacionais, atuantes em mercados variados, sendo que a empresa CampoOeste realiza integração com produtores. A distribuição dos farelos e óleos (refinado e bruto) de soja, produzidos no MS, têm como destino as regiões Sul e Sudeste do Brasil, uma parte da produção destina-se a países do MERCOSUL. Portanto fica muito perceptível a distinção de produção e beneficiamento pelas indústrias multinacionais, sendo assim o setor apresentou um grande crescimento nas últimas décadas (LIMA-FILHO et al., 2008).

\subsection{Cana-de-açúcar}

O aumento da demanda por biocombustíveis e bioenergia está crescendo a cada dia no mundo, e seus impactos podem ser observados em diversas cadeias produtivas que usam seus recursos e que competem pelas suas fontes de suprimentos (REIS et al., 2013).

A cadeia produtiva da cana-de-açúcar produz diversos produtos, pode-se citar: o Etanol Anidro e Hidratado, o Açúcar e Energia Elétrica. Enquanto o etanol e o açúcar são produtos concorrentes, ou seja, o aumento da produção do primeiro reduz a produção do segundo, a energia elétrica é gerada a partir do bagaço da cana-de-açúcar (DOMINGUES; THOMAZ-JÚNIOR, 2012).

Em MS pode-se observar o crescimento da entrada da atividade canavieira, a partir das toneladas de cana moída desde a primeira safra até os últimos anos que, segundo a CONAB (2014a), foi de $2.386,6$ toneladas na safra 1984/1985 e de 41.496,04 toneladas na safra 2013/2014. A área cultivada no país com cana-de-açúcar que será colhida e destinada à atividade sucroalcooleira na safra 2014/15 será de aproximadamente 9,4 milhões de hectares, distribuídas em todos estados produtores, sendo que a previsão de cultivo no MS será de aproximadamente $668,3 \mathrm{mil}$ hectares (CONAB, 2014b).
Segundo Domingues e ThomasJúnior (2012), o setor canavieiro vem sendo estimulado cada vez mais pelo Estado brasileiro, e a preocupação fundamental é a manutenção da lógica da reprodução do capital. Essas ações e discursos que justificam, pela via da expansão da monocultura da cana, desmatamento de terras, exploração/depredação dos recursos naturais locais (principalmente, a terra e a água), colocam os desafios iminentes para todos, ou seja, responder quais seriam os impactos na produção de alimentos.

Vale ressaltar que, além de apoio do governo, as empresas têm também o forte amparo do governo federal, que financia seus projetos com valores altos, pagamento em longo prazo e com juros baixos, que, às vezes, acabam por perdoar a dívida. Pode-se afirmar que o Zoneamento Agroecológico da Cana-de-Açúcar é uma forma de apoio do estado, pois direciona a expansão e, a partir dela, faz o planejamento para mais investimentos.

\subsection{Eucalipto}

Em 2012, existia no Brasil 5.102.030 ha de florestas plantadas com eucalipto, sendo que 587.310 ha se encontram em MS (11,5\%). A cadeia produtiva do setor brasileiro de base florestal associado às florestas plantadas caracteriza-se pela grande diversidade de produtos, compreendendo a produção, a colheita e o transporte de madeira, além da obtenção dos produtos finais nos segmentos industriais de Papel e Celulose, Painéis de Madeira Industrializada, Madeira Processada Mecanicamente, Siderurgia a Carvão Vegetal e Biomassa, entre outros (ASSOCIAÇÃO BRASILEIRA DE PRODUTORES DE FLORESTAS PLANTADAS [ABRAF], 2013).

A chegada das empresas de papel e celulose no município de Três Lagoas acaba por fazer com que a Região Leste de MS torne-se a principal área de expansão da eucalipcultura. Mesmo com as fábricas 
instaladas no município de Três Lagoas, os impactos sociais e ambientais são sentidos em toda a região pelo plantio de eucalipto nas antigas fazendas de gado, causando impactos negativos no campo e na cidade (FONSECA; THOMAZ JUNIOR, 2014).

Destaca-se a vantagem competitiva de MS em relação a outras regiões brasileiras para a produção de florestas. Enquanto em outras localidades a produtividade gira em torno de 25 metros cúbicos por hectare/ano, em MS esse valor chega a 35 metros cúbicos por hectare/ano. O maior impacto na economia sul-mato-grossense nos últimos anos provém exatamente da indústria de papel e celulose. No final de 2006, firmou-se o projeto de implantação de uma fábrica de papel e celulose na cidade de Três Lagoas com capacidade produtiva inicial de 200 mil toneladas/ ano. Essa implantação prevê um aumento no PIB do estado e na cidade de Três Lagoas (CHAEBO, et al., 2010).

\subsection{Pecuária}

O Brasil é o segundo maior produtor de carne bovina, sendo responsável por 9.307 mil toneladas de carne em 2012, ficando atrás apenas da produção americana, sendo que $75 \%$ da produção de carne bovina brasileira são para consumo interno representando aproximadamente de $37 \mathrm{Kg}$ per capita (CONAB, 2014c; MINISTÉRIO DA AGRICULTURA [MAPA], 2014). A região Centro-Oeste é responsável por 38\% do rebanho nacional, e MS possui 21.498.382 cabeças de gado e, em 2013, foi o segundo estado que mais abateu bovinos, cerca de 1.000.000 de cabeças (IBGE, 2012; 2013; ZEN, 2000). A pecuária é a atividade econômica mais importante e antiga no Pantanal (MITTERMEIER et al., 1990). Atualmente há cerca de 3,5 milhões de cabeças de gado, que utilizam basicamente pastagem nativa (POTT; POTT, 2004) e exóticas que invadem outras áreas, excluindo competitivamente as espécies nativas.
Na região Centro-Oeste, apenas 34\% das pastagens seguem o manejo adequado com corretivos e adubação, possibilitando a produção de $16,5 \mathrm{Kg}$ de carne por hectare/ano, em contrapartida, o pasto que não é manejado produz apenas $8,8 \mathrm{Kg}$ de carne hectare/ano com o mesmo número de animais (ZEN, 2000). Em MS, a maior parte da criação de bovinos é feita de forma extensiva, ou seja, com a engorda do boi sendo feita pelo pasto, com predomínio do gênero Urochloa (ÍTAVO et al., 2008).

Um dos principais insumos da pecuária é proveniente de sobras de plantas para produção da ração, além de sementes para pastagem, vacinas, medicamentos, melhoramento genético com inseminação artificial, dentre outros. Na parte de produção de gado, MS possui um sistema Semiextensivo, ou seja, além da pastagem o gado recebe suplementação com ração (CEZAR et al., 2005). O boi é uma matéria-prima riquíssima de interesse para o mercado, pois $100 \%$ da carcaça é aproveitada, fios cirúrgicos são feitos do intestino, os componentes sanguíneos são separados e originam vacinas, embutidos, fertilizantes, chifres transformam-se em pó de extintor, tendões e ligamentos são utilizados para fabricação de gelatinas, a gordura para o sorvete, o pelo para pincéis, o couro em bolsas, sapatos, dentre tantas outras utilidades que a carcaça proporciona (EMBRAPA, 2011). E o produto comestível, carne, é disponibilizado para comércio nacional e internacional.

Com a criação extensiva e sem o manejo adequado de pasto pela maioria dos produtores, o cenário visto nas fazendas de gado sul-mato-grossense é de degradação do solo e ambiental. Saindo dos perímetros urbanos das cidades do estado, vemos pastos quase ao todo descobertos, erosões, cupinzeiros, falta de proteção vegetal nos canais de água, gado bebendo água diretamente de cursos d'água e se alimentando do solo, dentre outros. Quando o produtor percebe que sua área de pasto não supre as necessidades do 
gado e está dando prejuízos financeiros, ao invés de fazer o manejo adequado desse pasto, alguns pecuaristas exploram novas áreas de vegetação nativa, ocasionando assim um ciclo vicioso de degradação. Por fim, a Embrapa (2013) ratifica que mais da metade do pasto do estado está degradado, pois de 15 milhões de hectares de pastagem, 9 milhões estão degradados.

Assim, é necessária uma fiscalização e órgãos de execução mais rígidos para que a exposição do solo e supressão de vegetação em pastagens não cheguem a níveis quase irreversíveis, pois existem práticas de manejo disponíveis para os produtores, com replantio de pasto, dentre outras maneiras, além da rotatividade de culturas e a integração lavoura, pecuária, floresta que permite a recomposição de nutrientes do solo, evitando a destruição de recursos finitos.

\subsection{Apicultura}

Dentre todas as atividades abordadas anteriormente, a apicultura é a única que é totalmente sustentável. É uma atividade na qual o homem cria abelhas do gênero Apis em colmeias artificiais visando à produção de mel, sendo esta uma boa opção para o agronegócio por ser uma atividade de uso sustentável, contribuindo para a manutenção das espécies nativas e aumento da produção agrícola (LOPES et al., 2001). As abelhas são importantes na polinização de inúmeras plantas, garantindo a imensa variabilidade genética característica da flora brasileira (CONCEIÇÃO et al. 2004 ). Além do mais, a apicultura pode ser integrada à agriculturas orgânica para aumento da produtividade com aumento de polinizadores. Também pode ser inserida em plantações de eucaliptos para produção de méis monoflorais, enquanto espera-se o período de corte do eucalipto.

Apicultura é uma atividade importante para o meio ambiente que exige diversidade floral para compor um pasto apícola anual. MS apresenta forte potencial para se tornar um grande produtor apícola devido à rica flora natural disponível, e, nos últimos anos, a produção de mel tem crescido substancialmente devido à organização dos apicultores do estado para aprimoramento das técnicas de produção. Em relação à sua cadeia produtiva, tudo que é produzido pode ser utilizado, pois, a partir da produção dos produtos apícolas pelas abelhas, o homem colhe os produtos como mel, pólen, geleia real e própolis e os embala para produto final. Assim, é uma atividade que pode ser exercida conjuntamente no meio rural, onde ocorre a produção dos produtos, e no meio urbano, onde se pode localizar o entreposto, que é o local onde os produtos serão embalados e disponibilizados para venda.

MS ainda é um pequeno produtor de mel, com representatividade apenas de $1,3 \%$ da produção nacional. No entanto o estado é o maior produtor do CentroOeste, com $41 \%$ da produção regional (BUAINAIN; BATALHA, 2007), e conta com grande potencial de produção, com áreas de Cerrado e Pantanal não cultivadas. Além destas, todas as regiões do Estado apresentam bom potencial para o desenvolvimento da atividade, tanto nas áreas de Mata Atlântica, localizadas ao sul, quanto nas regiões de Cerrado e Pantanal, que representam quase um terço do território sul-mato-grossense. Além da rica flora natural constituída pelas reservas permanentes, a agricultura e as florestas de eucaliptos completam o pasto apícola (REIS, 2003).

A flora nativa do Cerrado é um importante e rico pasto apícola tanto para as abelhas nativas quanto para Apis mellifera, que é a principal fonte produtora de mel. Com as áreas em estudo caracterizam ambientes onde a flora e fauna deveriam ser preservada, uma possibilidade de melhorar essa baixa produtividade é o reforço de plantas nativas apícolas ou mesmo sua reintrodução em alguns ambientes. Por exemplo, nas propriedades em que se deve 
fazer o reflorestamento de APP, a introdução da apicultura com abelhas nativas pode servir como meio de se diminuir os gastos com o reflorestamento através da produção e venda de produtos apícolas. Além do mais, as abelhas nessas áreas são de fundamental importância para polinização das flores, para que se formem sementes que são dispersas na área, para assim esta ser recomposta mais rápido. Portanto a apicultura pode, ao mesmo tempo, proporcionar renda e qualidade de vida, conservando o meio ambiente.

\section{CONSIDERAÇÕES FINAIS}

Com o crescimento do agronegócio em MS, é importante ressaltar a importância dos indicadores sustentáveis aliado com o Novo Código Florestal, através do reflorestamento das áreas frágeis com espécies nativas, principalmente a reposição da mata ciliar degradada, na maioria das vezes, pela pecuária ou até mesmo pelo cultivo desenfreado das culturas agrícolas nessas áreas. A inserção de abelhas nativas nessas áreas é um importante componente dentro dos indicadores ambientais, pois a apicultura, além de ser uma atividade sustentável e contribuir para a recomposição da área, também é economicamente viável na maioria das vezes e promove o bem-estar social, através das associações de apicultores para o desenvolvimento da área.

A agropecuária possui vícios ambientais como a poluição das águas pelos agrotóxicos, a dessedentação de animais de produção sendo feita diretamente nos cursos d'água e a supressão da mata ciliar são exemplos que propiciam a desestabilidade ambiental dessas áreas. Quanto à utilização do solo, ele tem sido utilizado até o esgotamento de todos os seus nutrientes sem a preocupação da recomposição dos minerais, tornando-os pobres e frágeis pela utilização extensiva, causando-lhe degradação (erosões, voçorocas etc.) e deixando-o impróprio para utilização futuras. Portanto é importante a recuperação e manutenção desses ambientes, sendo que a redução dessas áreas autorizadas pelo Novo Código Florestal causa um grande atraso para o meio ambiente.

Assim, é necessário estabelecer práticas sustentáveis no âmbito econômico, social e ambiental, através do uso de novas tecnologias e manejos que permitem igual ou maior produção sem o aumento das áreas já cultivadas. Dessa maneira, é necessário dispor de indicadores de sustentabilidade ambiental que proporcionem essas práticas, como exemplos:1) número máximo de cabeças de gado/ha que o solo possa comportar; 2) recomposição de pastagem; 3) rotatividade de culturas através de sistemas agrossilvipastoris; 4) recuperação da mata ciliar com a diversidade de espécies locais; 5) utilização de controle biológico; entre outros.

Portanto é possível expandir a produção agropecuária com práticas sustentáveis ao meio ambiente e de acordo com a lei vigente, um exemplo disso é o decreto que trata do Programa MS Mais Sustentável. Assim, mesmo que o Novo Código Florestal não tenha vindo agregar práticas de conservação, é importante que todos os proprietários de terra sigam as recomendações que estão na lei, por mais que sejam mínimas, mas pelo menos já se terá uma boa parcela de áreas recuperadas e protegidas, para que o estado de MS não passe o que o Estado de São Paulo passou no ano de 2014, com a escassez de água.

\section{Agradecimentos}

À Coordenação de Aperfeiçoamento de Pessoal de Nível Superior - CAPES pelas bolsas de estudo, por meio das quais contribuiu para o financiamento e desenvolvimento desta pesquisa.

\section{REFERÊNCIAS}

ASSOCIAÇÃO BRASILEIRA DE PRODUTORES DE FLORESTAS PLANTADAS (ABRAF). Anuário Estatístico da ABRAF, 2013. 
Disponível em: <http://www.abraflor.org. br/estatisticas.asp>. Acesso em: 9 nov. 2014.

BRASIL. Lei Federal n. 12.651, de 25 de maio de 2012. Dispõe sobre a proteção da vegetação nativa e dá outras providências. Diário Oficial [da] República Federativa do Brasil, Brasília, DF, 2012.

BUAINAIN, A. M.; BATALHA, M. O. Cadeia produtiva de flores e mel. Brasília: Ministério da Agricultura, Pecuária e Abastecimento/Secretaria de Política Agrícola; Instituto Interamericano de Cooperação para a Agricultura, 2007.

CEZAR, I. M. et al. Sistemas de produção de gado de corte no Brasil: uma descrição com ênfase no regime alimentar e no abate. Campo Grande, MS: Embrapa Gado de Corte, 2005.

CHAEBO, G. et al. Silvicultura em Mato Grosso do Sul: desafios e perspectivas a formulação de um arranjo produtivo local. In: CONGRESSO BRASILEIRO DA SOCIEDADE BRASILEIRA DE ECONOMIA, ADMINISTRAÇÃO E SOCIOLOGIA RURAL, 48., Campo Grande, MS, 25-28 jul. 2010. Anais... Campo Grande, MS: SOBER, 2010.

CHAVES, T. A. et al. Recuperação de áreas degradadas por erosão no meio rural. Niterói, RJ: Programa Rio Rural, 2012. 21p.

COMPANHIA NACIONAL DE ABASTECIMENTO (CONAB). Acompanhamento da Safra Brasileira de Grãos. Brasília, 2014a. Disponível em: <http:/ / www.conab.gov.br/OlalaCMS/uploads/arquivos/14_09_10_14_35_ 09_boletim_graos_setembro_2014.pdf $>$. Acesso em: 2 abr. 2015.

Segundo Levantamento de 2014 - Cana. Brasília, 2014b. Disponível em: <htpp:// www.conab.gov.br>. Acesso em: 9 nov. 2014.

Perspectivas para as carnes bovina, de frango e suina 2013-2014. 2014c. Disponível em: <http://www.conab.gov.br/OlalaCMS/ uploads/arquivos/13_09_12_17_43_13_09_ carnes.pdf> Acesso em: 10 nov. 2014.

CONCEIÇÃO, F. R. et al. Detecção de organismos geneticamente modificados. In: BINSFELD, P. C. Biossegurança em biotecnologia. Rio de Janeiro: Interciência, 2004. p. 145-169.

DOMINGUES, A. T. O setor agroindustrial canavieiro no Mato Grosso do Sul: desdobramentos e perspectivas. Revista Tamoios, v. 7, n. 2, p. 21-36, 2011.
DOMINGUES, A. T; THOMAZ-JÚNIOR, A. A territorialização da cana-de-açúcar no Mato Grosso do Sul. Caderno Prudentino de Geografia, v. 1, n. 34, p. 138-160, 2012.

EMPRESA BRASILEIRA DE PESQUISA AGROPECUÁRIA (EMBRAPA). Capacitação de técnicos e produtores em recuperação de áreas degradadas em Mato Grosso do Sul. 2013. Disponível em: <http://cloud.cnpgc.embrapa.br/ recupastagens2013/>. Acesso em:11 nov. 2014.

Subprodutos do boi. 2011. Disponível em: <http://ccw.sct.embrapa.br/? pg=bloguinho_default\&codigo=37>. Acesso em: 18 nov. 2014.

FAGUNDES, M. B. B.; SIQUEIRA, R. P. Caracterização do sistema agroindustrial da soja em Mato Grosso do Sul. Revista de Política Agrícola, ano 22, n. 3, jul./ago./set. 2013.

FONSECA, S. R.; THOMAZ JUNIOR, A. A consolidação do complexo de celulose e papel na região leste de Mato Grosso do Sul: estudo de caso do município de Selvíria. Revista Eletrônica da Associação dos Geógrafos Brasileiros, Três Lagoas, MS, v. 11, n. 19, maio 2014.

FOOD AND AGRICULTURE ORGANIZATION OF THE UNITED NATIONS (FAO). An ecosystem approach to sustainable crop production intensification: a conceptual framework. Disponível em: <http://www.fao.org/ fileadmin/templates/agphome/scpi/SCPI_ Compendium/SCPIConceptual_framework. pdf >. Acesso em: 18 nov. 2014.

GUIMARÃES, A. V. Mato Grosso do Sul, sua evolução histórica. 1. ed. Campo Grande, MS: UCDB, 1999.

HIRAKURI, M. H. et al. Indicadores de sustentabilidade da cadeia produtiva da soja no Brasil. Londrina, PR: Embrapa Soja, 2014. 37p.

INSTITUTO BRASILEIRO DE GEOGRAFIA E ESTATÍSTICA (IBGE). Mato Grosso do Sul: pecuária. 2012. Disponível em: <http:/ / www. ibge.gov.br/estadosat/temas.php?sigla $=$ ms\& tema=pecuaria2012> . Acesso em: 6 nov. 2014.

. Indicadores IBGE: estatística da produção pecuária. 2013. Disponível em: <http:/ / www.ibge.gov.br /home/estatistica/ indicadores/agropecuaria/producaoagropecuaria/abate-leite-couro-ovos_201303_publ_ completa.pdf>. Acesso em: 10 nov. 2014. 
ÍTAVO, L. C. V. et al. Desempenho produtivo, características de carcaça e avaliação econômica de bovinos cruzados, castrados e não-castrados, terminados em pastagens de Brachiaria decumbens. Arquivo Brasileiro de Medicina Veterinária e Zootecnia, v. 60, n. 5, 2008.

LIMA-FILHO, D. O. et al. Estratégias competitivas em agroindústrias selecionadas: estudo das principais cadeias produtivas de Mato Grosso do Sul. In: ENCONTRO NACIONAL DE ENGENHARIA DE PRODUÇÃO: A integração de cadeias produtivas com a abordagem da manufatura sustentável, 28. Rio de Janeiro, 13-16 out. 2008. Disponível em: < http://www.abepro.org.br/biblioteca/ enegep2008_tn_sto_075_534_11065.pdf>.

LIMA, W. P.; ZAKIA, M. J. B. Hidrologia de matas ciliares. In: RODRIGUES, R. R.; LEITÃO-FILHO, H. F. (Ed.). Matas ciliares: conservação e recuperação. 2. ed. São Paulo: Edusp/Fapesp, 2004. 320p.

LOPES, M. T. R. et al. Apicultura. Teresina, PI: Empresa Brasileira de Pesquisa Agropecuária Meio-Norte, 2001. 2p.

MATO GROSSO DOSUL [Estado]. Decreto Estadual n. 13.977 de 5 de junho de 2014. Dispõe sobre o Cadastro Ambiental Rural de Mato Grosso do Sul; sobre o Programa MS Mais Sustentável, e dá outras providências. Disponível em: <http:/ / www.legisweb.com.br/legislacao/?id=271190>. Acesso em: 14 nov. 2014.

MINISTÉRIO DA AGRICULTURA (MAPA). Mercado interno. Disponível em: <http:// www.agricultura.gov.br/animal/mercadointerno>. Acesso em: 10 nov. 2014.

MITTERMEIER, R. et al.Conservation in the Pantanal of Brazil. Oryx, v. 24, n. 2, p. 103-112, abr. 1990.

NOLTE,C.; AGRAWAL, A.; SILVIUS, K.M.; SOARES-FILHO, B.S; Governance regime and location influence avoided deforestation success of protected in the Brazilian Amazon. Proceedings of the National Academy of Sciences of the United States of America, v. 110, n. 13, p. 4956-4961, 2013. Disponível em: <http://www.pnas. org/content/110/13/4956.long>. Acesso em: 10 nov. 2014.

POTT, A.; POTT, V. J. Features and conservation of the brazilian Pantanal wetland. Wetlands Ecology and Management, v. 12, n. 6, p. 547-552, 2004.

REIS, J. G. M. et al. Desenvolvimento do setor sucroenergético no estado de Mato Grosso do Sul: impactos e benefícios da geração de energia a partir da produção de cana-de-açúcar. In: INTEGRATINGCLEANER PRODUCTIONINTO SUSTAINABILITY STRATEGIES. São Paulo, Brazil, May 22nd to $24^{\text {th }}$, 2013. Disponível em: <http://www.advancesincleanerproduction. net/fourth/files/sessoes/5A/4/reis_jgm_et_ al_work.pdf>.

REIS, V. D. A. Pré-diagnóstico da cadeia de produtos apícolas de Mato Grosso do Sul. Corumbá, MS: Embrapa Pantanal, 2003.

SANTOS, S. A.; COMASTRI-FILHO, J. A. Práticas de limpeza de campo para o Pantanal. Corumbá, MS: Embrapa, 2012.

SOUZA, C. B. M. A Bovinocultura de corte do estado de Mato Grosso do Sul: evolução e competitividade. 2010. 194f. Dissertação (Mestrado em Desenvolvimento Econômico) - Instituto de Economia da Universidade Estadual de Campinas (UNICAMP), Campinas, SP, 2010.

ZAKLA, M. J; PINTO, L. F. G. Guia para aplicação da nova lei florestal em propriedades rurais. Piracicaba, SP: Imaflora, 2013. 32p.

ZEN, S. Aspectos da produção de carne e as tendências do mercado nacional. In: SIMPÓSIO DE PRODUÇÃO DE GADO DE CORTE, 1. Anais... São Paulo: USP, 2000

\section{Sobre as autoras:}

Natascha Góes Cintra Borlachenco: Professora da Universidade Estadual de Mato Grosso do Sul, doutoranda do Programa Ciências Ambientais e Sustentabilidade Agropecuária da Universidade Católica Dom Bosco. E-mail: nacintra@hotmail.com

Ariadne Barbosa Gonçalves: Doutoranda do Programa Ciências Ambientais e Sustentabilidade Agropecuária da Universidade Católica Dom Bosco. E-mail: ariadne.gon@gmail.com 